Article

\title{
Antioxidant and Cytoprotective Effects of the Di-O-Caffeoylquinic Acid Family: The Mechanism, Structure-Activity Relationship, and Conformational Effect
}

\author{
Xican $\mathrm{Li}^{1,2, *,+}{ }^{\dagger}, \mathrm{Ke} \mathrm{Li}^{3,4,{ }^{\dagger}}$, Hong Xie ${ }^{1,2}$, Yulu Xie ${ }^{1,2}$, Yueying $\mathrm{Li}^{1}$, Xiaojun Zhao ${ }^{1,2}$, \\ Xiaohua Jiang ${ }^{5}$ and Dongfeng Chen ${ }^{3,4, *}$ \\ 1 School of Chinese Herbal Medicine, Guangzhou University of Chinese Medicine, \\ Waihuan East Road No. 232, Guangzhou Higher Education Mega Center, Guangzhou 510006, China; \\ xiehongxh1@163.com (H.X.); xieyulu1900@163.com (Y.X.); 1ln@gzucm.edu.cn (Y.L.); zxj@gzucm.edu.cn (X.Z.) \\ Innovative Research \& Development Laboratory of TCM, Guangzhou University of Chinese Medicine, \\ Waihuan East Road No. 232, Guangzhou Higher Education Mega Center, Guangzhou 510006, China \\ 3 School of Basic Medical Science, Guangzhou University of Chinese Medicine, Waihuan East Road No. 232, \\ Guangzhou Higher Education Mega Center, Guangzhou 510006, China; ys1090992678@163.com \\ 4 The Research Center of Basic Integrative Medicine, Guangzhou University of Chinese Medicine, \\ Waihuan East Road No. 232, Guangzhou Higher Education Mega Center, Guangzhou 510006, China \\ 5 School of Biomedical Sciences, Faculty of Medicine, The Chinese University of Hong Kong, Sha Tin, \\ Hong Kong 999077, China; xjiang@cuhk.edu.hk \\ * Correspondence: lixican@126.com (X.L.); chen888@gzucm.edu.cn (D.C.); Tel.: +86-203-935-8076 (X.L.) \\ + These authors contributed equally to this work.
}

Received: 8 December 2017; Accepted: 18 January 2018; Published: 20 January 2018

\begin{abstract}
In this study, a series of di-O-caffeoylquinic acids (di-COQs) were systematically investigated for their antioxidant and cytoprotective effects towards $\bullet \mathrm{OH}$-damaged bone marrow-derived mesenchymal stem cells (bmMSCs). Five di-COQs were measured using a set of antioxidant assays. The results show that adjacent 4,5-Di-O-caffeoylquinic acid (4,5-COQ) and 3,4-di-O-caffeoylquinic acid $(3,4-\mathrm{COQ})$ always gave lower $\mathrm{IC}_{50}$ values than did non-adjacent di-COQs. In the $\mathrm{Fe}^{2+}$-chelating assay, 4,5-COQ and 3,4-COQ presented greater UV-Vis spectra and darker colors than did non-adjacent di-COQs. In the UPLC-ESI-MS/MS analysis, no corresponding radical adduct formation (RAF) peak was found in the reaction products of di-COQs with PTIO•. In the MTT assay, all di-COQs (especially 1,5-COQ, 1,3-COQ, and 4,5-COQ) dose-dependently increased the cellular viabilities of - OH-damaged bmMSCs. Based on this evidence, we conclude that the five antioxidant di-COQs can protect bmMSCs from $\bullet \mathrm{OH}$-induced damage. Their antioxidant mechanisms may include electron-transfer (ET), $\mathrm{H}^{+}$-transfer, and $\mathrm{Fe}^{2+}$-chelating, except for RAF. Two adjacent di-COQs (4,5-COQ and 3,4-COQ) always possessed a higher antioxidant ability than the non-adjacent di-COQs (1,3-COQ, 1,5-COQ, and 3,5-COQ) in chemical models. However, non-adjacent 1,3-COQ and 1,5-COQ exhibited a higher cytoprotective effect than did adjacent di-COQs. These differences can be attributed to the relative positions of two caffeoyl moieties and, ultimately, to the conformational effect from the cyclohexane skeleton.
\end{abstract}

Keywords: conformational effect; caffeoylquinic acids; antioxidant; cytoprotective effect

\section{Introduction}

The activity of synthetic and natural antioxidants is derived from the molecular phenolic moiety, but it can be affected by structural factors such as hydrogen-bonding [1], the amount of phenolic 
-OHs [2,3], O-methylation [4], glycosidation [5], anisylation [6], and heterocycles [6]. Even the 6"-OH group of the sugar residue in flavonoid glycosides could alter the antioxidant levels [7].

However, these structural factors are limited to molecular "structure" and are not involved in the molecular "conformation." From the perspective of organic chemistry [8], molecular conformation derives from the $\sigma$-bond free rotation, which can alter the spatial relative position of the moieties (or atoms). A representative example is the cyclohexane molecule, which can give two distinctive conformations: chair conformation and boat conformation. The chair conformation has been proven to be preferential; in it, the axial bond ( $a$ bond) and equatorial bond ( $e$ bond) are alternately arrayed. The difference between the $a$ bond and $e$ bond results in the chemical characteristics of the moieties (or atoms), which has been called the conformational effect. Recently, the conformational effect has been found to change some of the chemical properties, such as red-shifted emission, of luciferin [9]. It is hypothesized that, if an antioxidant moiety is attached to the cyclohexane skeleton and occupies different bond types ( $a / e$ bonds), its antioxidant potential may be distinctive. However, such conformational effects towards antioxidant ability have not, to our knowledge, yet been reported.

In this study, five di-O-caffeoylquinic acids (di-COQ), which are distributed in different plants [10-14], were selected as references for the conformational effect investigation. As shown in Figure 1, the five di-COQs comprise 1,3-di-O-caffeoylquinic acid (1,3-COQ), 1,5-di-O-caffeoylquinic acid (1,5-COQ), 3,4-di-O-caffeoylquinic acid (3,4-COQ), 3,5-di-O-caffeoylquinic acid (3,5-COQ), and 4,5-di-O-caffeoylquinic acid (4,5-COQ). In the five molecules, the caffeoyl moiety, with antioxidant potential, is attached to hexacyclic quinic acid; thus, these five acids may be the ideal reference for such an investigation.

It is worth noting that some of these compounds have already been explored for their antioxidant ability using a DPPH•-scavenging assay, ABTS $\bullet^{+}$-scavenging assay, anti-low-density lipoprotein (LDL) oxidation assay [11,15], and cellular assay [13]. However, each of these studies was based on the plant origin: Hung focused on antioxidants from Dipsacus asper, Zhang only explored antioxidants in Lonicera japonica, and Wan was only engaged in the phytochemical work of Chrysanthemum coronarium [14]. Thus, for di-COQs, these works are non-systematical. For instance, the phytochemical work of Wan lacks 1,3-COQ [14] and is irrelevant to the antioxidant study, and Hung's work lacks two important members: 1,3-COQ and 1,5-COQ. However, some mono-O-caffeoylquinic acids (e.g., chlorogenic acid) and flavonoids were involved in these studies [10,11,14]. Hence, these works are non-comparative and cannot be used to analyze the structure-activity relationship of the di-COQs antioxidant family.

The present study, however, used five di-COQs for comparative study, based on chemical and cellular models. The cellular model is based on oxidatively stressed bone marrow-derived mesenchymal stem cells (bmMSCs). bmMSCs are considered a highly promising cell type candidate for cell-based tissue transplantation engineering and regeneration, but they are limited by their lower cellular viability derived from oxidative stress [16]. Our study will also provide new information about the di-COQs family regarding bmMSCs transplantation engineering. 


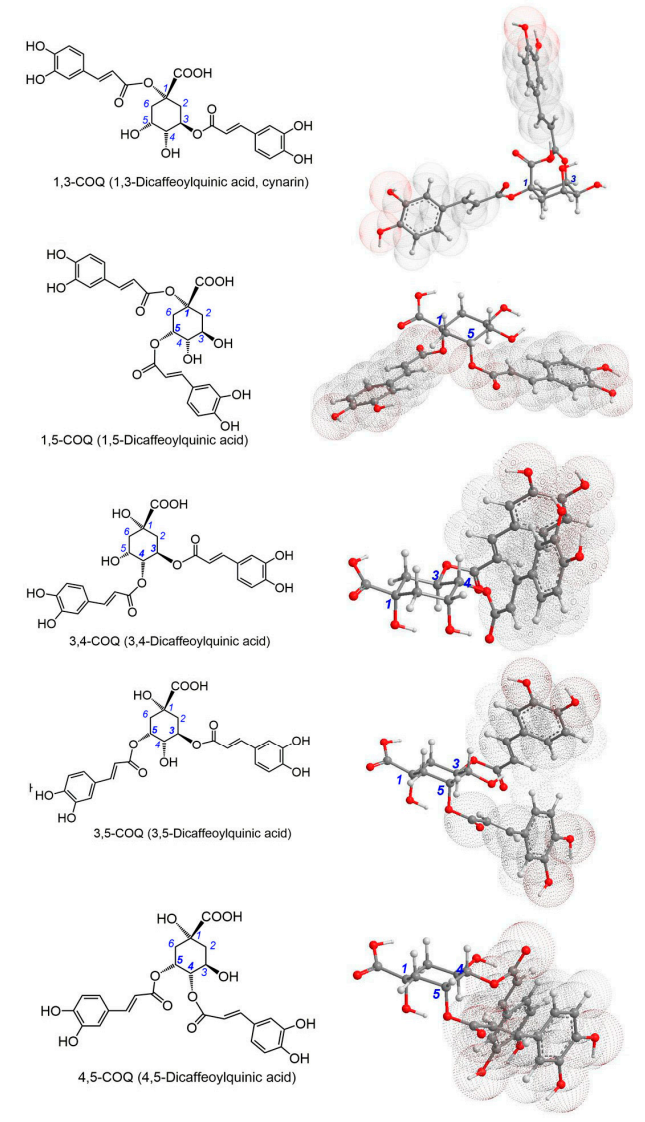

Figure 1. Structures (left) and preferential conformation-based ball-stick models (right) of five di-O-caffeoylquinic acids (di-COQs). The ball-stick models were created in Chem3D Pro 14.0. The screenshots from models are from the same perspective; i.e., C-1 was deposited on the right end, and $-\mathrm{COOH}$ is upward. The three-dimensional perspective animations are shown in Video S1-5. However, the relative degree of crowd for caffeoyl moieties remains unchanged.

\section{Results and Discussion}

Iron overload can induce oxidative stress to severely damage cells, which can cause a series of diseases (including neurodegeneration), resulting from the ability of iron (particularly $\mathrm{Fe}^{2+}$ ) to promote the generation of ROS [17]. A typical example is the Fenton reaction, which can produce $\bullet \mathrm{OH}$ radicals. Thus, iron chelation has now been developed as a therapy for these diseases [18,19], and the iron chelation level of a natural antioxidant is regularly evaluated using colorimetric methods and UV-Vis spectra analysis $[20,21]$. However, UV-Vis spectra analysis is considered direct evidence of an iron chelating reaction $[22,23]$.

In the present study, we used UV-Vis spectra to analyze the $\mathrm{Fe}^{2+}$-chelating ability of the five di-COQs. As shown in Figure 2, after incubation with $\mathrm{Fe}^{2+}$, each of the five di-COQs gave rise to an absorption maximum around $750 \mathrm{~nm}$ and a green product mixture, suggesting that an $\mathrm{Fe}^{2+}$-chelating reaction between $\mathrm{Fe}^{2+}$ and each of the di-COQs occurs. Therefore, each of the di-COQs may undergo an $\mathrm{Fe}^{2+}$-chelating approach to reduce the oxidative stress from $\mathrm{ROS}$ (especially $\bullet \mathrm{OH}$ ). A typical $\mathrm{Fe}^{2+}$-chelating reaction could be proposed, as shown in Figure 3. Since $\mathrm{Fe}^{2+}$-chelating can indirectly release oxidative stress, it is sometimes called the indirect antioxidant mechanism.

Correspondingly, radical-scavenging is termed a direct antioxidant mechanism. In this study, five di-COQs were observed to dose-dependently scavenge various radicals in chemical models, including $\mathrm{PTIO} \bullet, \mathrm{DPPH} \bullet$, and $\mathrm{ABTS}^{+} \bullet$ radicals (Figure S1). PTIO• is an oxygen-centered radical, whereas both $\mathrm{DPPH} \bullet$ and $\mathrm{ABTS}^{+} \bullet$ are nitrogen-centered radicals. The ability of the five di-COQs to 
scavenge the three radicals implies that they can scavenge not only ROS but also reactive nitrogen species (RNS, e.g., $\mathrm{ONOO}^{-}$and NO) in cells and may undergo a direct antioxidant approach to reduce the oxidative stress.

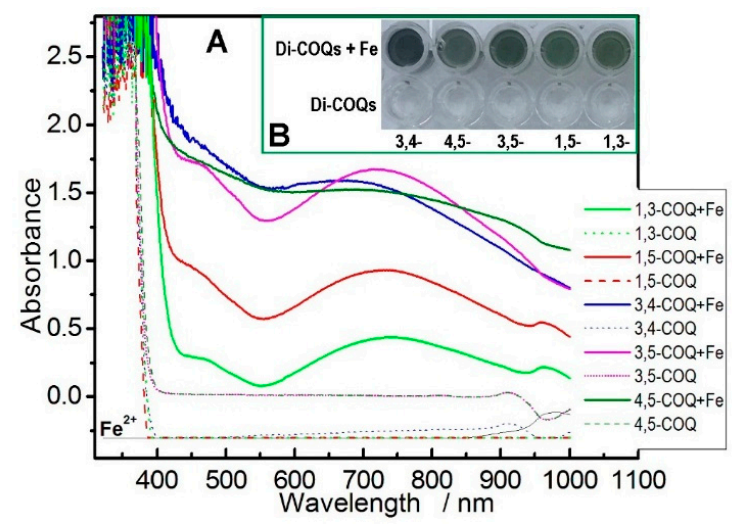

Figure 2. (A) UV-Vis spectra of the five di-COQs and their chelating products with excess $\mathrm{Fe}^{2+}$. (B) The colors of complexes, resulting from the product mixtures, were taken by a camera.

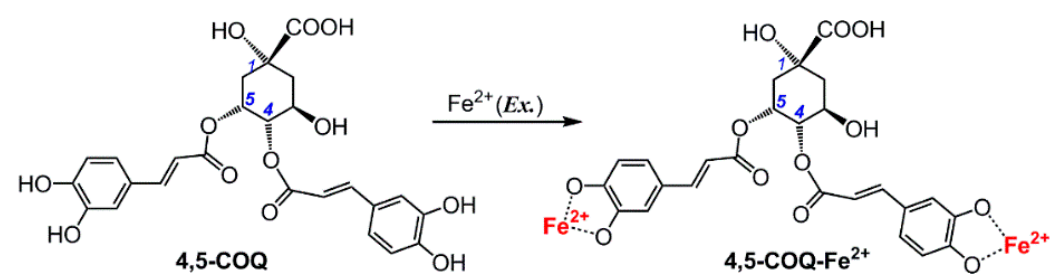

Figure 3. The proposed chelating reaction of 4,5-COQ (4,5-di-O-caffeoylquinic acid) with excessive $\mathrm{Fe}^{2+}$ (the reaction formula is proposed based on previous studies [11,22-24]).

Furthermore, these free radical-scavenging reactions are mediated by different antioxidant pathways. PTIO• scavenging at $\mathrm{pH} 4.5$ is an electron transfer (ET) pathway [25]. The effectiveness of the five di-COQs with PTIO• scavenging at $\mathrm{pH} 4.5$ shows that they can undergo ET to exert their antioxidant action, which is further supported by evidence from the FRAP assay, a mere ET process [26].

However, PTIO• scavenging at $\mathrm{pH} 7.4$ was proven to be an $\mathrm{H}^{+}$-transfer pathway [27]. Since the five di-COQs can efficiently scavenge PTIO• at $\mathrm{pH} 7.4$, this implies that a $\mathrm{H}^{+}$-transfer may play a role in their antioxidant action. It is worth noting that the so-called ET or $\mathrm{H}^{+}$-transfer is a unidirectional process, where the antioxidant donates an electron or $\mathrm{H}^{+}$to the radical rather than the antioxidant accepting an electron or $\mathrm{H}^{+}$from the radical $[21,27,28]$.

Unlike the FRAP assay (or PTIO• scavenging at pH 4.5), DPPH•-scavenging and $\mathrm{ABTS}^{+} \bullet$-scavenging assays are mediated via complicated pathways. DPPH•-scavenging includes multiple hydrogen atom transfer (HAT)-based pathways [27], and $\mathrm{ABTS}^{+} \bullet$ is scavenged through multiple ET-based pathways [26]. The DPPH•-scavenging and $\mathrm{ABTS}^{+} \bullet$-scavenging by the five di-COQs indicated that their antioxidant actions may also be fulfilled via multiple antioxidant pathways, including $\mathrm{H}^{+}$-transfer, ET, and HAT.

It should be noted that the radical adduct formation (RAF) may also occur in the radical-scavenging action of phenolic antioxidants [28,29]. However, no RAF product peak was observed in the UPLC-ESI-MS/MS spectra of the di-COQs reaction products with PTIO•. By comparison, chlorogenic acid (a mono-O-caffeoylquinic acid) generated a peak at $m / z 708$, which is the value of the chlorogenic acid-chlorogenic acid dimer (Figure S2). This suggests that the five di-COQs cannot mediate RAF to exert the antioxidant action. The inactivity of di-COQs in the RAF pathway is presumed to be from steric hindrance, although this presumption needs further identification. Therefore, the evidence from 
the chemical models indicated that as natural antioxidants, di-COQs may undergo multiple antioxidant pathways (including $\mathrm{H}^{+}$-transfer, ET, or HAT, but not RAF) to exert their antioxidant action.

From the perspective of quantitative analysis, the $\mathrm{IC}_{50}$ values of the five di-COQs were different from each other (Table 1), which indicates that there are differences in the relative antioxidant levels. In general, adjacent di-COQs (4,5-COQ and 3,4-COQ) always possess higher levels than do non-adjacent di-COQs (1,3-COQ, 1,5-COQ, and 3,5-COQ). Interestingly, the relative levels are similar to the anti-inflammatory activities [30].

Table 1. The $\mathrm{IC}_{50}$ values of five di-COQs in various antioxidant assays.

\begin{tabular}{|c|c|c|c|c|c|}
\hline Compounds & $\begin{array}{c}\text { PTIO॰-Scavenging } \\
\text { (pH 4.5, mg/mL, mM) }\end{array}$ & $\begin{array}{l}\text { PTIO• Scavenging } \\
\text { (pH 7.4, mg/mL, mM) }\end{array}$ & FRAP $(\mu \mathrm{g} / \mathrm{mL}, \mu \mathrm{M})$ & $\begin{array}{l}\text { DPPH•-Scavenging } \\
(\mu \mathrm{g} / \mathrm{mL}, \mu \mathrm{M})\end{array}$ & $\begin{array}{c}\text { ABTS }^{+} \bullet-S c a v e n g i n g \\
(\mu \mathrm{g} / \mathrm{mL}, \mu \mathrm{M})\end{array}$ \\
\hline 1,3-COQ & $\begin{array}{c}47.2 \pm 1.6 \\
\left(91.4 \pm 3.6^{\mathrm{e}}\right)\end{array}$ & $\begin{array}{c}57.7 \pm 1.0 \\
\left(111.8 \pm 2.0^{\mathrm{c}}\right)\end{array}$ & $\begin{array}{c}3.4 \pm 0.2 \\
\left(6.5 \pm 0.4^{c}\right)\end{array}$ & $\begin{array}{c}2.9 \pm 0.1 \\
\left(5.7 \pm 0.3^{\mathrm{b}}\right)\end{array}$ & $\begin{array}{c}3.6 \pm 0.0 \\
\left(6.9 \pm 0.1^{\mathrm{c}}\right)\end{array}$ \\
\hline 1,5-COQ & $\begin{array}{c}35.5 \pm 2.8 \\
\left(68.7 \pm 5.4^{\mathrm{d}}\right)\end{array}$ & $\begin{array}{c}63.0 \pm 7.6 \\
\left(121.9 \pm 14.8^{\mathrm{c}}\right)\end{array}$ & $\begin{array}{c}3.3 \pm 0.1 \\
\left(6.4 \pm 0.2^{c}\right)\end{array}$ & $\begin{array}{c}4.7 \pm 0.6 \\
\left(9.2 \pm 1.1^{\mathrm{c}}\right)\end{array}$ & $\begin{array}{c}3.5 \pm 0.0 \\
\left(6.7 \pm 0.1^{c}\right)\end{array}$ \\
\hline 3,4-COQ & $\begin{array}{c}19.1 \pm 0.4 \\
\left(37.0 \pm 0.5^{\mathrm{c}}\right)\end{array}$ & $\begin{array}{c}22.3 \pm 6.2 \\
\left(43.1 \pm 12.0^{\mathrm{b}}\right)\end{array}$ & $\begin{array}{c}2.6 \pm 0.1 \\
\left(5.1 \pm 0.2^{b}\right)\end{array}$ & $\begin{array}{c}2.9 \pm 0.5 \\
\left(5.7 \pm 0.9^{\mathrm{b}}\right)\end{array}$ & $\begin{array}{c}3.2 \pm 0.0 \\
\left(6.2 \pm 0.1^{b}\right)\end{array}$ \\
\hline 3,5-COQ & $\begin{array}{c}55.9 \pm 2.6 \\
\left(108.0 \pm 5.1^{f}\right)\end{array}$ & $\begin{array}{c}60.2 \pm 2590 \\
\left(116.5 \pm 5.0^{c}\right)\end{array}$ & $\begin{array}{c}3.4 \pm 0.0 \\
\left(6.7 \pm 0.1^{\mathrm{c}}\right)\end{array}$ & $\begin{array}{c}3.2 \pm 0.5 \\
\left(6.1 \pm 0.9^{b}\right)\end{array}$ & $\begin{array}{c}3.6 \pm 0.1 \\
\left(7.0 \pm 0.3^{c}\right)\end{array}$ \\
\hline 4,5-COQ & $\begin{array}{c}4.3 \pm 0.3 \\
\left(8.3 \pm 0.3^{\mathrm{b}}\right)\end{array}$ & $\begin{array}{c}23.3 \pm 0.3 \\
\left(45.2 \pm 0.6^{\mathrm{b}}\right)\end{array}$ & $\begin{array}{c}2.6 \pm 0.1 \\
\left(3.4 \pm 2.9^{\mathrm{a}}\right)\end{array}$ & $\begin{array}{c}1.7 \pm 0.9 \\
\left(3.4 \pm 1.8^{\mathrm{a}}\right)\end{array}$ & $\begin{array}{c}2.8 \pm 0.0 \\
\left(5.4 \pm 0.1^{\mathrm{a}}\right)\end{array}$ \\
\hline Trolox & $\begin{array}{c}33.4 \pm 0.5 \\
\left(0.1 \pm 0.0^{\mathrm{a}}\right)\end{array}$ & $\begin{array}{c}26.8 \pm 1.5 \\
\left(0.1 \pm 0.0^{\mathrm{a}}\right)\end{array}$ & $\begin{array}{c}16.4 \pm 2.9 \\
\left(31.7 \pm 5.5^{\mathrm{d}}\right)\end{array}$ & $\begin{array}{c}6.2 \pm 0.0 \\
\left(12.0 \pm 0.1^{\mathrm{d}}\right)\end{array}$ & $\begin{array}{c}6.9 \pm 0.1 \\
\left(13.4 \pm 0.2^{d}\right)\end{array}$ \\
\hline
\end{tabular}

The $\mathrm{IC}_{50}$ value (in $\mu \mathrm{g} / \mathrm{mL}$ unit) was defined as the final concentration of $50 \%$ radical inhibition or relative reducing power, calculated by linear regression analysis, and expressed as the mean $\pm \operatorname{SD}(n=3)$. The linear regression was analyzed by Origin 6.0 professional software. The $\mathrm{IC}_{50}$ value was also expressed in $\mu \mathrm{M} / \mathrm{mM}$ unit. The $\mathrm{IC}_{50}$ value in the $\mu \mathrm{M} / \mathrm{mM}$ unit, with different superscripts $(\mathrm{a}, \mathrm{b}, \mathrm{c}, \mathrm{d}, \mathrm{e}, \mathrm{or} \mathrm{f})$ in the same diagram, are significantly different $(p<0.05)$. Trolox is the positive control. 1,3-COQ: 1,3-di-O-caffeoylquinic acid; 1,5-COQ: 1,5-di-O-caffeoylquinic acid; 3,4-COQ: 3,4-di-O-caffeoylquinic acid; 3,5-COQ: 3,5-di-O-caffeoylquinic acid; 4,5-COQ: 4,5-di-O-caffeoylquinic acid. The dose-response curves are listed in Figure S1.

As shown in Figure 1 (right), 4,5-COQ and 3,4-COQ contain two adjacent caffeoyl moieties and belong to adjacent di-COQs. Caffeoyl moieties are attached to the chair conformation-preferred hexacyclic skeleton, where the $\boldsymbol{a}$ and $\boldsymbol{e}$ bonds are alternately arrayed [9]. In 4,5-COQ, two caffeoyl moieties present a trans-configuration; in 3,4-COQ, however, two caffeoyl moieties display a cis-configuration. Despite having two adjacent caffeoyl moieties in a trans-configuration and an $e$ bond, they are still very crowded. The degree of crowd increases the molecular energy, thereby elevating the redox potential. Thus, in the redox-based antioxidant assays, 4,5-COQ and 3,4-COQ, which contain two adjacent caffeoyl moieties, are always more effective than are the three non-adjacent di-COQs (1,3-COQ, 1,5-COQ, and 3,5-COQ). In each of the three non-adjacent di-COQs, two caffeoyl moieties are distant from each other, regardless of the $a / e$ bonds and trans-/cis- configurations. The distance effectively releases the crowd to decrease the molecular energy and redox reactivity. Correspondingly, the antioxidant potential has been lowered.

The difference between adjacent and non-adjacent di-COQs can also be observed in the $\mathrm{Fe}^{2+}$-chelating assay. As shown in Figure 2A, compared by three non-adjacent di-COQs, both 4,5-COQ and 3,4-COQ gave stronger peaks in the UV spectra when treated by excessive $\mathrm{Fe}^{2+}$. In the aspect of complex color, 4,5-COQ and 3,4-COQ also yielded a darker color than did the three non-adjacent di-COQs (Figure 2B). These results imply that adjacent 4,5-COQ and 3,4-COQ also displayed a higher $\mathrm{Fe}^{2+}$-chelating ability than did the three non-adjacent di-COQs.

In each member of the di-COQs family, the ligand for the $\mathrm{Fe}^{2+}$-chelating reaction is the caffeoyl moiety [11]. As shown in Figure 1 (right), two caffeoyl moieties in 3,4-COQ and 4,5-COQ molecules stretch out of the skeleton on the same side, in which they can surround excessive $\mathrm{Fe}^{2+}$ to participate in the chelating reaction. In contrast, two caffeoyl moieties in non-adjacent di-COQs (especially 1,3-COQ and 1,5-COQ) extended from two directions and can hardly surround excessive $\mathrm{Fe}^{2+}$ for joint chelation. As a result, 3,4-COQ and 4,5-COQ are more effective $\mathrm{Fe}^{2+}$-chelators than are the three non-adjacent di-COQs. It should be noted that the dihydroxyl groups in the quinic acid ring cannot 
chelate metals to form a stable ringed complex, such as the 4,5-dihydroxyl groups in 1,3-COQ and the 3,4-dihydroxyl groups in 1,5-COQ [21,23,31]. In a word, two adjacent di-COQs (4,5-COQ and 3,4-COQ) always possess a higher antioxidant ability than the three non-adjacent di-COQs (1,3-COQ, 1,5-COQ, and 3,5-COQ) in chemical models.

In the cellular model, their relative cytoprotective levels exhibit only small changes. As shown in Table 2, all five di-COQs could concentration-dependently enhance the viability percentages of $\bullet \mathrm{OH}$-treated bmMSCs in the MTT assay. Furthermore, $1,3-\mathrm{COQ}, 1,5-\mathrm{COQ}$, and 4,5-COQ gave higher viability percentages than did the other compounds. Generally speaking, two non-adjacent di-COQs (1,3-COQ and 1,5-COQ) exhibit a higher cytoprotective effect than adjacent di-COQs. It is hypothesized that 1,3-COQ and 1,5-COQ exhibited a better cytoprotective effect due to their molecular shapes. In 1,3-COQ and 1,5-COQ, two caffeoyl moieties extend from the molecule in different directions, resulting in a long and narrow structure, which may help them freely cross the cytomembrane to the nucleus. However, the above hypothesis requires further study. In short, these differences among the five di-COQs in terms of antioxidant or cytoprotective effects may result from the conformation of the coral cyclohexane skeleton.

Table 2. The viability percentages of five di-COQs towards $\bullet \mathrm{OH}$-damaged bmMSCs in the MTT assay.

\begin{tabular}{|c|c|c|c|c|c|c|}
\hline Compounds & Control & Model & $10 \mu \mathrm{g} / \mathrm{mL}$ & $30 \mu \mathrm{g} / \mathrm{mL}$ & $50 \mu \mathrm{g} / \mathrm{mL}$ & $100 \mu \mathrm{g} / \mathrm{mL}$ \\
\hline 1,3-COQ & $100 \%$ & $12.67 \%$ & $17.03 \%$ * & $20.23 \%$ * & $23.97 \%$ * & $47.15 \%$ * \\
\hline $1,5-\mathrm{COQ}$ & $100 \%$ & $12.67 \%$ & $19.09 \%$ * & $21.65 \%$ * & $24.90 \%$ * & $44.93 \%$ * \\
\hline $3,4-\mathrm{COQ}$ & $100 \%$ & $12.67 \%$ & $13.02 \%$ & $13.97 \%$ & $15.53 \%$ * & $21.15 \%$ * \\
\hline 3,5-COQ & $100 \%$ & $12.67 \%$ & $13.06 \%$ & $16.21 \%$ * & $19.55 \%$ * & $23.38 \%$ * \\
\hline $4,5-\mathrm{COQ}$ & $100 \%$ & $12.67 \%$ & $14.14 \%$ & $21.78 \%$ * & $22.72 \%$ * & $42.04 \%$ * \\
\hline
\end{tabular}

Experiments were performed with 3 different batches of cells and each batch was tested in triplicate. The Fenton reagent $\left(\mathrm{FeCl}_{2}\right.$ plus $\left.\mathrm{H}_{2} \mathrm{O}_{2}\right)$ was used to generate $\bullet \mathrm{OH}$ radicals. These data represent the mean $\pm \mathrm{SD}$ $(n=3) .{ }^{*} p<0.05$ vs. model. MTT, 3-(4,5-dimethylthiazol-2-yl)-2,5-diphenyltetrazolium bromide. 1,3-COQ: 1,3-di-O-caffeoylquinic acid; 1,5-COQ: 1,5-di-O-caffeoylquinic acid; 3,4-COQ: 3,4-di-O-caffeoylquinic acid; 3,5-COQ: 3,5-di-O-caffeoylquinic acid; 4,5-COQ: 4,5-di-O-caffeoylquinic acid.

\section{Materials and Methods}

\subsection{Chemicals and Animals}

1,3-Di-O-caffeoylquinic acid (CAS 30964-13-7, 97\%), 1,5-di-O-caffeoylquinic acid (CAS 19870-46-3, 97\%), 3,4-di-O-caffeoylquinic acid (CAS 14534-61-3, 97\%), 3,5-di-O-caffeoylquinic acid (CAS 2450-53-5, 97\%), and 4,5-di-O-caffeoylquinic acid (CAS 57378-72-0, 97\%) were obtained from Chengdu Biopurify Phytochemicals Ltd. (Chengdu, China). The 1,1-diphenyl-2-picryl-hydrazl radical (DPPH•), $( \pm)$-6-hydroxyl-2,5,7,8-tetramethlychromane-2-carboxylic acid (Trolox), 2,4,6-tripyridyltriazine (TPTZ), and 3-(4,5-dimethylthiazol-2-yl)-2,5-diphenyltetrazolium bromide (MTT) were purchased from Sigma-Aldrich Shanghai Trading Co. (Shanghai, China). $\left(\mathrm{NH}_{4}\right)_{2} \mathrm{ABTS}$ [2,2'-azino-bis(3-ethylbenzo-thiazoline-6-sulfonic acid diammonium salt)] was obtained from Amresco Chemical Co. (Solon, OH, USA). The 2-phenyl-4,4,5,5-tetramethylimidazoline-1-oxyl-3-oxide radical (PTIO•) was from TCI Chemical Co. (Shanghai, China). Dulbecco's modified Eagle's medium (DMEM), fetal bovine serum (FBS), and trypsin were purchased from Gibco (Grand Island, NY, USA). CD44 and Proteinase K were purchased from Wuhan Boster Co., Ltd. (Wuhan, China). All other reagents were of analytical grade.

Sprague-Dawley (SD) rats of 4 weeks of age were obtained from the Animal Center of Guangzhou University of Chinese Medicine (Guangzhou, China). The protocol of this experiment was performed under the supervision of the Institutional Animal Ethics Committee in Guangzhou University of Chinese Medicine (Approval number 20170306A). 


\subsection{UV-Vis Spectra Analysis of $\mathrm{Fe}^{2+}$-Chelating with di-COQs}

This method was based on the previous study [20]. Briefly, $100 \mu \mathrm{L}$ of a methanolic solution of di-COQs $(3 \mathrm{mg} / \mathrm{mL})$ was added to $400 \mu \mathrm{L}$ of an aqueous solution of $\mathrm{FeCl}_{2} \cdot 4 \mathrm{H}_{2} \mathrm{O}(10 \mathrm{mg} / \mathrm{mL})$. The solution was then mixed vigorously. Subsequently, the resulting mixture was incubated at room temperature for $30 \mathrm{~min}$, and the spectrum was obtained using a UV-Vis spectrophotometer (Jinhua 754 PC, Shanghai, China) from $200-1000 \mathrm{~nm}$. Then, $200 \mu \mathrm{L}$ of the supernatant was transferred to a 96-well plate and photographed using a camera.

\subsection{PTIO•-Scavenging Assay}

The PTIO•-scavenging assay was conducted based on our method [32]. In brief, $80 \mu \mathrm{L}$ of an aqueous PTIO• solution $(0.1 \mathrm{mM})$ was mixed with $20 \mu \mathrm{L}$ of phosphate buffer $(\mathrm{pH} 4.5,7.4)$ containing sample $(5 \mathrm{mg} / \mathrm{mL})$ at the indicated concentrations. The mixture was maintained at $37^{\circ} \mathrm{C}$ for $2 \mathrm{~h}$, and the absorbance was measured at $560 \mathrm{~nm}$ on a microplate reader (Multiskan FC, Thermo Scientific, Shanghai, China). The PTIO• inhibition percentage was calculated as follows:

$$
\text { Scavenging } \%=\frac{A_{0}-A}{A_{0}}
$$

where $A_{0}$ indicates the absorbance of the blank and $A$ indicates the absorbance of the sample.

\subsection{FRAP Assay}

The FRAP assay was established by Benzie and Strain [33]. In the present study, the FRAP reagent was prepared freshly by mixing $10 \mathrm{mM} \mathrm{TPTZ}, 20 \mathrm{mM} \mathrm{FeCl}_{3}$, and $0.25 \mathrm{M}$ acetate buffer (pH 3.6) at 1:1:10. The sample solution $(x=1-9 \mu \mathrm{L}, 0.1 \mathrm{mg} / \mathrm{mL})$ was added to $(20-x) \mu \mathrm{L}$ of $95 \%$ ethanol followed by $80 \mu \mathrm{L}$ of FRAP reagent. After incubation at ambient temperatures for $30 \mathrm{~min}$, the absorbance was measured at $595 \mathrm{~nm}$ using distilled water as the blank. The relative reducing power of the sample was calculated using the formula:

$$
\text { Relative reducing effect } \%=\frac{A-A_{\min }}{A_{\max }-A_{\min }}
$$

where $A_{\max }$ is the maximum absorbance, and $A_{\min }$ is the minimum absorbance in the test. $A$ is the absorbance of sample.

\subsection{DPPH•-Scavenging Assay}

$\mathrm{DPPH} \bullet$ radical-scavenging activity was determined as previously described [34]. Briefly, $80 \mu \mathrm{L}$ of DPPH• solution $(0.1 \mathrm{~mol} / \mathrm{L})$ was mixed with the indicated concentrations of sample $(0.05 \mathrm{mg} / \mathrm{mL}$, $2-10 \mu \mathrm{L}$ ) dissolved in methanol. The mixture was maintained at room temperature for $30 \mathrm{~min}$, and the absorbance was measured at $519 \mathrm{~nm}$ on a microplate reader. The percentage of DPPH• scavenging activity was calculated based on the formula presented in Section 3.3.

\subsection{ABTS•+'-Scavenging Assay}

The ABTS $\bullet{ }^{+}$-scavenging activity was evaluated according to the method [24]. The ABTS $\bullet{ }^{+}$was produced by mixing $0.2 \mathrm{~mL}$ of $\left(\mathrm{NH}_{4}\right)_{2} \mathrm{ABTS}(7.4 \mathrm{mmol} / \mathrm{L})$ with $0.35 \mathrm{~mL}$ of potassium persulfate $(2.6 \mathrm{mmol} / \mathrm{L})$. The mixture was kept in the dark at room temperature for $12 \mathrm{~h}$ to allow completion of radical generation and then diluted with distilled water (about 1:20), so that its absorbance at $734 \mathrm{~nm}$ was measured on a microplate reader. To determine the scavenging activity, the test sample $(x=1-9 \mu \mathrm{L}$, $0.1 \mathrm{mg} / \mathrm{mL})$ was added to $(20-\mathrm{x}) \mu \mathrm{L}$ of distilled water followed by $80 \mu \mathrm{L}$ of ABTS $\bullet^{+}$reagent, and the absorbance at $734 \mathrm{~nm}$ was measured $3 \mathrm{~min}$ after the initial mixing, using distilled water as the blank. The percentage inhibition of the samples was calculated based on the formula listed in Section 3.3. 


\subsection{UPLC-ESI-Q-TOF-MS/MS Analysis of Reaction Products of di-COQs and Chlorogenic Acid with PTIO•}

This method was based on the previous study [27]. The methanol solution of di-COQs was mixed with a solution of PTIO• radical in methanol at a molar ratio of 1:2, and the resulting mixture was incubated for $24 \mathrm{~h}$ at room temperature. The product mixture was then filtered through a $0.22 \mu \mathrm{m}$ filter and analyzed using a UPLC-ESI-Q-TOF-MS/MS system equipped with a $\mathrm{C}_{18}$ column ( $2.0 \mathrm{~mm}$ i.d. $\times 100 \mathrm{~mm}, 2.2 \mu \mathrm{m}$, Shimadzu Co., Kyoto, Japan). The mobile phase was used for the elution of the system and consisted of a mixture of methanol (Phase A) and water (Phase B). The column was eluted at a flow rate of $0.3 \mathrm{~mL} / \mathrm{min}$ with the following gradient elution program: 0-10 $\mathrm{min}$, $60 \%-100 \% \mathrm{~A} ; 10-15 \mathrm{~min}, 100 \% \mathrm{~A}$. The sample injection volume was set at $1 \mu \mathrm{L}$ for the separation of the different components. Q-TOF-MS/MS analysis was performed on a Triple TOF 5600 ${ }^{\text {plus }}$ Mass spectrometer (AB SCIEX, Framingham, MA, USA) equipped with an ESI source, which was run in the negative ionization mode. The scan range was set at 100-2000 Da. The system was run with the following parameter: ion spray voltage: $-4500 \mathrm{~V}$; ion source heater: $550{ }^{\circ} \mathrm{C}$; curtain gas (CUR, $\mathrm{N}_{2}$ ): 30 psi; nebulizing gas (GS1, Air): 50 psi; Tis gas (GS2, Air): 50 psi. The declustering potential (DP) was set at $-100 \mathrm{~V}$, whereas the collision energy (CE) was set at $-40 \mathrm{~V}$ with a collision energy spread (CES) of $20 \mathrm{~V}$. The RAF products were quantified by extracting corresponding formula (e.g., $\left[\mathrm{C}_{43} \mathrm{H}_{36} \mathrm{~N}_{5} \mathrm{O}_{18}-\mathrm{H}\right]^{-}$for di-COQs-DPPH•) from the Total Ion Chromatogram, integrating the corresponding peak. We used chlorogenic acid as a positive control to repeat the above experiments, instead of di-COQs.

\subsection{Cytoprotective Effect towards $\bullet O H$-Damaged bmMSCs (MTT Assay)}

The bmMSCs were cultured according to our previous report [35] with slight modifications. In brief, bone marrow was obtained from the femur and tibia of rat. The marrow samples were diluted with DMEM (low glucose) containing 10\% FBS. The bmMSCs were prepared by gradient centrifugation at $900 \mathrm{~g}$ for $30 \mathrm{~min}$ on $1.073 \mathrm{~g} / \mathrm{mL}$ Percoll. The prepared cells were detached by treatment with $0.25 \%$ trypsin and passaged into cultural flasks at $1 \times 10^{4} / \mathrm{cm}^{2}$. The bmMSCs at Passage 3 were evaluated for cultured cell homogeneity.

The MTT assay was used to evaluate cytoprotective effect of di-COQs towards bmMSCs [34,36,37]. The experimental protocol is briefly illustrated in Figure 4.

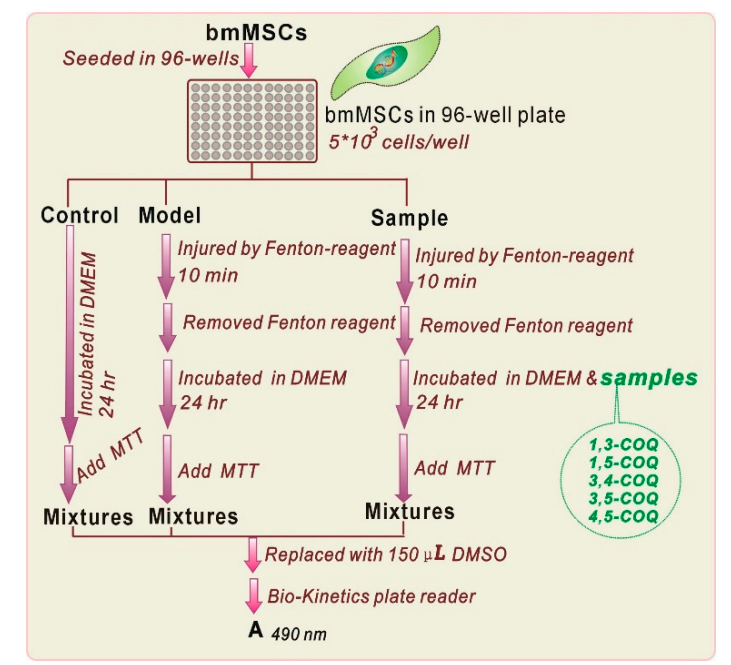

Figure 4. Experimental procedures for the MTT assay. (PE-1420 Bio-Kinetics reader: Bio-Kinetics Corporation, Sioux Center, IA, USA. Each test was repeated in five independent wells. MTT was used at $5 \mathrm{mg} / \mathrm{mL}$ (in PBS), and the addition volume was $20 \mu \mathrm{L}$. The addition of Fenton reagent was conducted by injection of $\mathrm{FeCl}_{2}(100 \mu \mathrm{M})$ followed by $\mathrm{H}_{2} \mathrm{O}_{2}(50 \mu \mathrm{M})$. 


\subsection{Statistical Analysis}

Each experiment was performed in triplicate and the data were recorded as mean $\pm \mathrm{SD}$ (standard deviation). The dose response curves were plotted using Origin 6.0 professional software (OriginLab, Northampton, MA, USA). The $\mathrm{IC}_{50}$ value was defined as a final concentration of $50 \%$ radical inhibition (or relative reducing power) [38]. Statistical comparisons were made by one-way ANOVA to detect significant difference using SPSS 13.0 (SPSS Inc., Chicago, IL, USA) for Windows. $p<0.05$ was considered to be statistically significant.

\section{Conclusions}

Five antioxidant di-COQs can protect bmMSCs from $\bullet \mathrm{OH}$-induced damage. Their antioxidant mechanisms may include $\mathrm{ET}, \mathrm{H}^{+}$-transfer, and $\mathrm{Fe}^{2+}$-chelating, except for $\mathrm{RAF}$. However, the antioxidant (or cytoprotective) levels are different among them. These differences can be attributed to the positions of the two caffeoyl moieties and, ultimately, to the conformational effect from the cyclohexane skeleton.

Supplementary Materials: The following are available online. Video S1-5: Animations of 1,3-COQ, 1,5-COQ, 3,4-COQ, 3,5-COQ, and 4,5-COQ. Figure S1: Dose response curves of five di-COQs in various assays. Figure S2: Original Data of UPLC-ESI-MS/MS analysis.

Acknowledgments: This work was supported by the Guangdong Science and Technology Project (2017A030312009, 2017A050506043) and the National Nature Science Foundation of China (81573558).

Author Contributions: Xican Li, Xiaohua Jiang, and Dongfeng Chen conceived and designed the experiments; Yueying Li, Hong Xie, and Xiaojun Zhao performed the antioxidant experiments; Ke Li performed the MTT assay; Yulu Xie analyzed the data; Xican Li wrote the paper. All authors read and approved the final manuscript.

Conflicts of Interest: The authors declare that they have no competing interests.

\section{Abbreviations}

The following abbreviations are used in this manuscript:

$\begin{array}{ll}\text { 1,3-COQ } & \text { 1,3-di-O-caffeoylquinic acid } \\ \text { 1,5-COQ } & \text { 1,5-di-O-caffeoylquinic acid } \\ \text { 3,4-COQ } & \text { 3,4-di-O-caffeoylquinic acid } \\ \text { 3,5-COQ } & \text { 3,5-di-O-caffeoylquinic acid } \\ \text { 4,5-COQ } & \text { 4,5-di-O-caffeoylquinic acid } \\ \text { ABTS } & \text { [2,2'-azino-bis(3-ethylbenzo-thiazoline-6-sulfonic acid diammonium salt)] } \\ \text { bmMSCs } & \text { bone marrow-derived mesenchymal stem cells } \\ \text { DMEM } & \text { Dulbecco's modified Eagle's medium } \\ \text { DPPH• } & \text { (1,1-diphenyl-2-picryl-hydrazl) } \\ \text { ET } & \text { electron transfer } \\ \text { FBS } & \text { fetal bovine serum } \\ \text { FRAP } & \text { ferric reducing antioxidant power } \\ \text { HAT } & \text { hydrogen atom transfer } \\ \text { PTIO• } & \text { 2-phenyl-4,4,5,5-tetramethylimidazoline-1-oxyl 3-oxide radical } \\ \text { ROS } & \text { reactive oxygen species } \\ \text { RNS } & \text { reactive nitrogen species } \\ \text { RAF } & \text { radical adduct formation } \\ \text { SD } & \text { standard deviation } \\ \text { TPTZ } & \text { 2,4,6-tris(2-pyridyl-s-triazine) } \\ \text { Trolox } & \text { [( } \pm \text { )-6-hydroxyl-2,5,7,8-tetramethlychromane-2-carboxylic acid] }\end{array}$

\section{References}

1. Liliana, M. Intramolecular hydrogen bonding and conformational preferences of arzanol—An antioxidant acylphloroglucinol. Molecules 2017, 22, 1294. 
2. Li, X.; Chen, D.; Mai, Y.; Wen, B.; Wang, X. Concordance between antioxidant activities in vitro and chemical components of Radix Astragali (Huangqi). Nat. Prod. Res. 2012, 26, 1050-1053. [CrossRef] [PubMed]

3. Wang, T.; Zeng, G.; Li, X.; Zeng, H. In vitro studies on the antioxidant and protective effect of 2-substituted8-hydroxyquinoline derivatives against $\mathrm{H}_{2} \mathrm{O}_{2}$-induced oxidative stress in BMSCs. Chem. Biol. Drug Des. 2010, 75, 214-222. [CrossRef] [PubMed]

4. Heim, K.E.; Tagliaferro, A.R.; Bobily, D.J. Flavonoid antioxidants: Chemistry, metabolism and structureactivity relationships. J. Nutr. Biochem. 2002, 13, 572-584. [CrossRef]

5. Li, X.C.; Liu, J.J.; Lin, J.; Wang, T.T.; Huang, J.Y.; Lin, Y.Q.; Chen, D.F. Protective effects of dihydromyricetin against $\bullet \mathrm{OH}$-induced mesenchymal stem cells damage and mechanistic chemistry. Molecules 2016, 21, 604. [CrossRef] [PubMed]

6. Wang, G.; Li, X.; Zeng, H. Synthesis, antioxidation activity of (E)-9-p-Tolyl-3-[2-(8-hydroxy-quinol-2yl)vinyl]-carbazole and (E)-9-(p-Anisyl)-3-[2-(8-hydroxy-quinol-2-yl)vinyl]-carbazole and their induction proliferation of mesenchymal stem cells. Acta Chim. Sin. 2009, 67, 974-982.

7. Li, X.C.; Jiang, Q.; Wang, T.T.; Liu, J.J.; Chen, D.F. Comparison of the antioxidant effects of quercitrin and isoquercitrin: Understanding the role of the 6"-OH group. Molecules 2016, 21, 1246. [CrossRef] [PubMed]

8. Graham Solomons, T.W.; Fryhle, C.B. Organic Chemistry, 8th ed.; Chemical Industry Press: Beijing, China, 2004; p. 167.

9. Berraud-Pache, R.; Navizet, I. QM/MM calculations on a newly synthesised oxyluciferin substrate: New insights into the conformational effect. Phys. Chem. Chem. Phys. 2016, 18, 27460-27467. [CrossRef] [PubMed]

10. Cho, J.Y.; Kim, J.Y.; Lee, Y.G.; Lee, H.J.; Shim, H.J.; Lee, J.H.; Kim, S.J.; Ham, K.S.; Moon, J.H. Four New Dicaffeoylquinic Acid Derivatives from Glasswort (Salicornia herbacea L.) and Their Antioxidative Activity. Molecules 2016, 21, 1097. [CrossRef] [PubMed]

11. Hung, T.M.; Na, M.; Thuong, P.T.; Su, N.D.; Sok, D.; Song, K.S.; Seong, Y.H.; Bae, K. Antioxidant activity of caffeoyl quinic acid derivatives from the roots of Dipsacus asper Wall Tran. J. Ethnopharmacol. 2006, 108, 188-192. [CrossRef] [PubMed]

12. Ma, J.; Li, N.; Li, X. Caffeoylquinic acid derivatives from leaves of Lonicera japonica. Zhongguo Zhong Yao Za Zhi 2009, 34, 2346-2348. [PubMed]

13. Yu, B.; Li, J.L.; Guo, B.B.; Fan, H.M.; Zhao, W.M.; Wang, H.Y. Chlorogenic acid analogues from Gynura nepalensis protect $\mathrm{H} 9 \mathrm{c} 2$ cardiomyoblasts against $\mathrm{H}_{2} \mathrm{O}_{2}$-induced apoptosis. Acta Pharmacol. Sin. 2016, 37, 1413-1422. [CrossRef] [PubMed]

14. Wan, C.; Li, S.; Liu, L.; Chen, C.; Fan, S. Caffeoylquinic acids from the aerial parts of Chrysanthemum coronarium L. Plants 2017, 6, 10. [CrossRef] [PubMed]

15. Wang, D.; Du, N.; Wen, L.; Zhu, H.; Liu, F.; Wang, X.; Du, J.; Li, S. An efficient method for the preparative isolation and purification of flavonoid glycosides and caffeoylquinic acid derivatives from leaves of lonicera japonica thunb. Using high speed counter-current chromatography (HSCCC) and prep-HPLC guided by DPPH-HPLC experiments. Molecules 2017, 22, 229.

16. Denu, R.A.; Hematti, P. Effects of oxidative stress on mesenchymal stem cell biology. Oxid. Med. Cell. Longev. 2016, 2016, 2989076. [CrossRef] [PubMed]

17. Ivars, D.; Orero, M.T.; Javier, K.; Díaz-Vico, L.; García-Giménez, J.L.; Mena, S.; Tormos, C.; Egea, M.; Pérez, P.L.; Arrizabalaga, B.; et al. Oxidative imbalance in low/intermediate-1-risk myelodysplastic syndrome patients: The influence of iron overload. Clin. Biochem. 2017, 50, 911-917. [CrossRef] [PubMed]

18. Chiueh, C.C. Iron overload, oxidative stress, and axonal dystrophy in brain disorders. Pediatr. Neurol. 2001, 25, 138-147. [CrossRef]

19. Murillo-Ortiz, B.; Ramírez Emiliano, J.; Hernández Vázquez, W.I.; Martínez-Garza, S.; Solorio-Meza, S.; Albarrán-Tamayo, F.; Ramos-Rodríguez, E.; Benítez-Bribiesca, L. Impact of oxidative stress in premature aging and iron overload in hemodialysis patients. Oxid. Med. Cell. Longev. 2016, 2016, 1578235. [CrossRef] [PubMed]

20. Liu, J.; Li, X.; Lin, J.; Li, Y.; Wang, T.; Jiang, Q.; Chen, D. Sarcandra glabra (Caoshanhu) protects mesenchymal stem cells from oxidative stress: A bioevaluation and mechanistic chemistry. BMC Complement. Altern. Med. 2016, 16, 423. [CrossRef] [PubMed]

21. Li, X.; Han, W.; Mai, W.; Wang, L. Antioxidant activity and mechanism of Tetrahydroamentoflavone in vitro. Nat. Prod. Commun. 2013, 8, 787-789. 
22. Přemysl, M.; Kateřina, M.; Tomáš, F.; Libuše, Z.; Luděk, J.; Paolo, B.; Ilaria, P.S.; Radomír, H.; Luciano, S. In vitro analysis of iron chelating activity of flavonoids. Org. Biochem. 2011, 105, 693-701.

23. Mira, L.; Fernandez, M.T.; Santos, M.; Rocha, R.; Florêncio, M.H.; Jennings, K.R. Interactions of flavonoids with iron and copper ions: A mechanism for their antioxidant activity. Free Radic. Res. 2002, 36, 1199-1208. [CrossRef] [PubMed]

24. Li, X.C.; Mai, W.Q.; Chen, D.F. Chemical study on protective effect against hydroxyl-induced DNA damage and antioxidant mechanism of myricitrin. J. Chin. Chem. Soc. 2014, 61, 383-391. [CrossRef]

25. Goldstein, S.; Russo, A.; Samuni, A. Reactions of PTIO and Carboxy-PTIO with $\bullet \mathrm{NO}, \bullet \mathrm{NO}_{2}$, and $\mathrm{O}_{2}$. Biol. Chem. 2003, 278, 50949-50955. [CrossRef] [PubMed]

26. Gülçin, İ. Antioxidant activity of food constituents: An overview. Arch. Toxicol. 2012, 86, 345-391. [CrossRef] [PubMed]

27. Lin, J.; Li, X.; Chen, L.; Lu, W.; Chen, X.; Han, L.; Chen, D. Protective effect against hydroxyl radical-induced DNA damage and antioxidant mechanism of [6]-gingerol: A Chemical Study. Bull. Korean Chem. Soc. 2014, 35, 1633-1638. [CrossRef]

28. Li, X.; Gao, Y.; Li, F.; Liang, A.; Xu, Z.; Bai, Y.; Mai, W.; Han, L.; Chen, D. Maclurin protects against Hydroxyl radical-induced damages to mesenchymal stem cells: Antioxidant evaluation and mechanistic insight. Chem. Biol. Interact. 2014, 219, 221-228. [CrossRef] [PubMed]

29. Osman, A.M.; Wong, K.K.Y.; Fernyhough, A. ABTS radical-driven oxidation of polyphenols: Isolation and structural elucidation of covalent adducts. Biochem. Biophys. Res. Commun. 2006, 34, 6321-6329. [CrossRef] [PubMed]

30. Song, Y.L.; Wang, H.M.; Ni, F.Y.; Wang, X.J.; Zhao, Y.W.; Huang, W.Z.; Wang, Z.Z.; Xiao, W. Study on anti-inflammatory activities of phenolic acids from Lonicerae Japonicae Flos. Chin. Tradit. Herb. Drugs 2015, 46, 490-495.

31. Jiang, Q.; Li, X.; Tian, Y.; Lin, Q.; Xie, H.; Lu, W.; Chi, Y.; Chen, D. Lyophilized aqueous extracts of Mori Fructus and Mori Ramulus protect mesenchymal stem cells from $\bullet \mathrm{OH}$-treated damage: Bioassay and antioxidant mechanism. BMC Complement. Altern. Med. 2017, 17, 242. [CrossRef] [PubMed]

32. Li, X. 2-Phenyl-4,4,5,5-tetramethylimidazoline-1-oxyl 3-oxide (PTIO•) Radical-scavenging: A New and simple antioxidant assay in vitro. Agric. Food Chem. 2017, 65, 6288-6297. [CrossRef] [PubMed]

33. Benzie, I.F.; Strain, J.J. The ferric reducing ability of plasma (FRAP) as a measure of "antioxidant power": The FRAP assay. Anal. Biochem. 1996, 239, 70-76. [CrossRef] [PubMed]

34. Li, X.; Wei, G.; Wang, X.; Liu, D.; Deng, R.; Li, H.; Zhou, J.; Li, Y.; Zeng, H.; Chen, D. Targeting of the Shh pathway by atractylenolides promotes chondrogenic differentiation of mesenchymal stem cells. Biol. Pharm. Bull. 2012, 35, 1328-1335. [CrossRef] [PubMed]

35. Chen, D.; Li, X.; Xu, Z.; Liu, X.; Du, S.; Li, H.; Zhou, J.; Zeng, H.; Hua, Z. Hexadecanoic acid from Buzhong Yiqi decoction induces proliferation of bone marrow mesenchymal stem cells. J. Med. Food 2010, 13, 967-970. [CrossRef] [PubMed]

36. Li, X.; Hu, Q.; Jiang, S.; Li, F.; Lin, J.; Han, L.; Hong, Y.; Lu, W.; Gao, Y.; Chen, D. Flos Chrysanthemi Indici protects against hydroxyl-induced damages to DNA and MSCs via antioxidant mechanism: A chemistry study. J. Saudi Chem. Soc. 2015, 19, 454-460. [CrossRef]

37. Li, X.; Han, L.; Li, Y.; Zhang, J.; Chen, J.; Lu, W.; Zhao, X.; Lai, Y.; Chen, D.; Wei, G. Protective effect of sinapine against hydroxyl radical-induced damage to mesenchymal stem cells and possible mechanisms. Chem. Pharm. Bull. 2016, 64, 319-325. [CrossRef] [PubMed]

38. Li, X.; Wu, X.; Huang, L. Correlation Between Antioxidant Activities and Phenolic Contents of Radix Angelicae Sinensis (Danggui). Molecules 2009, 14, 5349-5361. [PubMed]

Sample Availability: Samples of the compounds are available from the authors. 